\title{
Noninvasive Respiratory Support in Neonates: A Review of Current Evidence and Practices
}

\author{
Rajendra Prasad Anne ${ }^{1} \cdot$ Srinivas Murki $^{2}$ (D)
}

Received: 23 January 2021 / Accepted: 26 March 2021 / Published online: 1 June 2021

(C) Dr. K C Chaudhuri Foundation 2021

\begin{abstract}
Respiratory distress is a common problem seen in neonates, both preterm and full term. Appropriate use of respiratory support can be life-saving in these neonates. While invasive ventilation is unavoidable in some situations, noninvasive ventilation may be sufficient in several neonates. In this review article, the authors have summarized the current evidence and the best practices to deliver effective noninvasive respiratory support.
\end{abstract}

Keywords Respiratory distress $\cdot$ Noninvasive respiratory support $\cdot$ CPAP $\cdot$ NIV $\cdot$ NIMV $\cdot$ NHFOV

\section{Introduction}

In 1971, Gregory and colleagues reported successful use of endotracheal tube continuous positive airway pressure (CPAP) in neonates [1]. Very soon, there were several reports of successful use of noninvasive CPAP in treating neonates with respiratory distress syndrome (RDS), by a nasal interface [2] or a sealed head box [3]. However, the use of CPAP has taken a back seat with the introduction of neonatal ventilators which delivered intermittent mandatory ventilation (IMV) and positive end-expiratory pressure (PEEP). After two decades, in late 1980 s, there was a renewed interest in the use of CPAP after the report by Avery et al., which highlighted the use of CPAP as primary mode in Columbia Presbyterian Medical Centre and resultant decrease in rates of bronchopulmonary dysplasia (BPD) [4]. In the last three decades, nasal CPAP/noninvasive ventilation (NIV) has gradually emerged as the first choice of respiratory support in preterm neonates.

Srinivas Murki

srinivasmurki2001@gmail.com

1 Department of Neonatology, Newborn Unit, Fernandez Hospitals, Unit 2, Hyderguda, Hyderabad, Telangana, India

2 Department of Neonatology, Newborn Unit, Paramita Children's Hospital, Kothapet, L B Nagar, Hyderabad, Telangana 500074, India

\section{What is Noninvasive Ventilation (NIV)?}

NIV refers to any method of providing respiratory support, where an endotracheal tube is not used. The various methods include oxygen administration through a hood box or nasal cannula, heated, humidified high-flow nasal cannula (HHHFNC or HFNC), nasal CPAP (nCPAP), nasal intermittent positive-pressure ventilation (NIPPV), nasal bilevel positive airway pressure (nBiPAP), nasal high-frequency oscillatory ventilation (nHFOV), and nasal neurally adjusted ventilator assist (nNAVA). All these devices are driven by a gas flow, which can be with or without a pressure generator (HFNC); pressure generated at a single level (CPAP) or at two levels (NIPPV and BiPAP). In the following discussion, the authors describe each of these modalities used for delivering NIV in neonates (Fig. 1).

\section{High-Flow Nasal Cannula (HFNC)}

HFNC works by providing inhaled gases at flows higher than the inspiratory demand flow. This leads to wash out of upper airways, reduces physiological dead space, and decreases nasopharyngeal airway resistance. It also provides variable positive end expiratory pressure and decreases work of breathing. But, as delivering HFNC requires a loose-fitting nasal prong, the pressure delivery is not reliable. The three important components of HFNC include a flow generator, an air-oxygen blender, and a heater-humidifier (Fig. 1). HFNC has gained popularity because of the ease of use, lesser nasal trauma, and more comfort to the neonate. 
Fig. 1 Increasing complexity in modes of noninvasive respiratory support. BiPAP Bilevel positive airway pressure; $C P A P$

Continuous positive airway pressure; HFNC High-flow nasal cannula; $n H F O V$ Nasal high frequency oscillatory ventilation; NIPPV Noninvasive positive pressure ventilation; $\mathrm{O}_{2}$ Oxygen

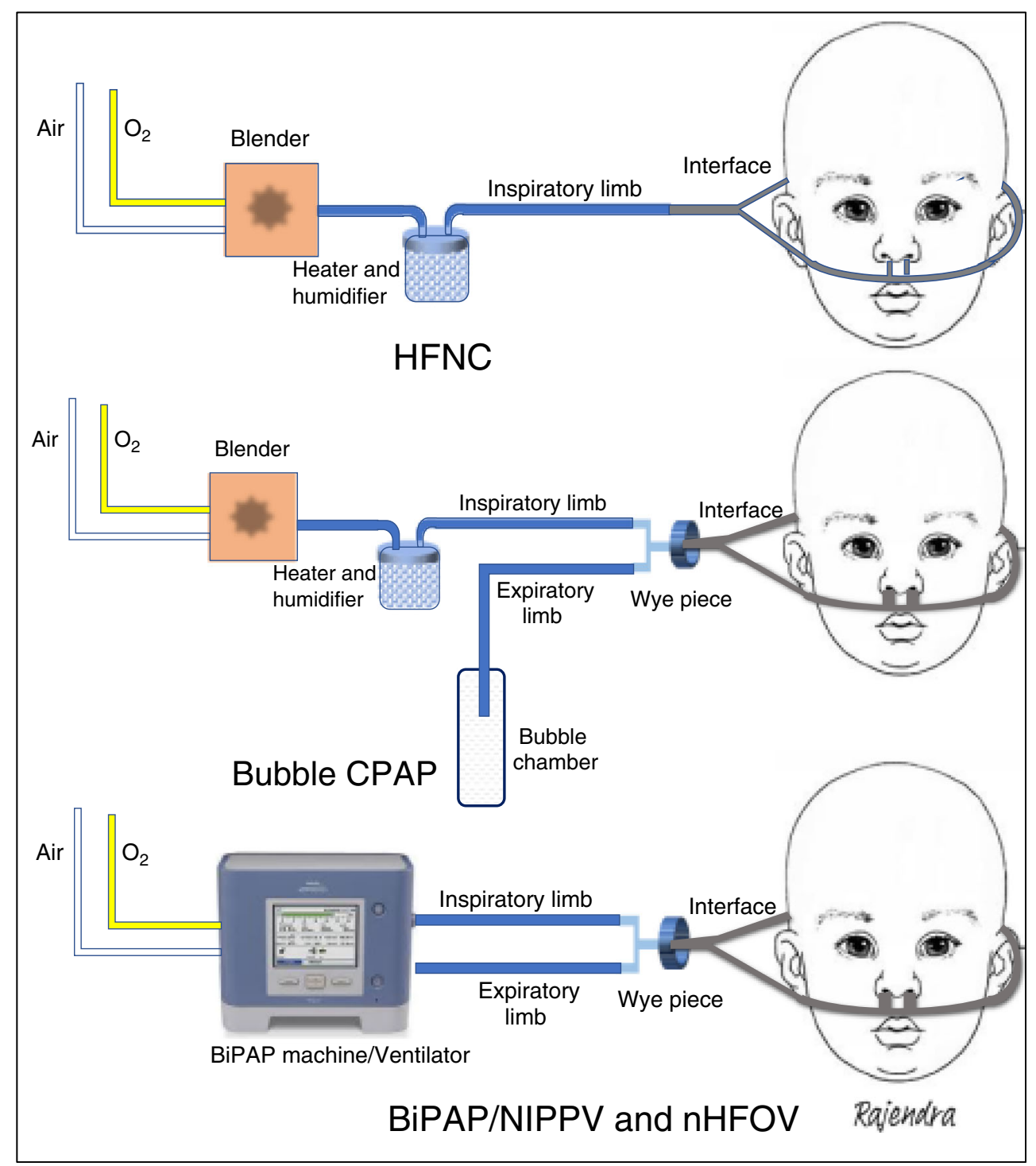

HFNC is administered either with a stand-alone HFNC machines (Optiflow ${ }^{\mathrm{TM}}$ or Vapotherm ${ }^{\mathrm{TM}}$ ) or by a modification of CPAP circuit where the expiratory limb is removed. The flow rates for neonates range from 4 to $8 \mathrm{~L} / \mathrm{min}$, with the gases delivered at $37^{\circ} \mathrm{C}$ and $100 \%$ relative humidity.

The current evidence suggests that HFNC (across all indications) does not increase the risk of treatment failure or need for mechanical ventilation (MV) compared to nCPAP. Moreover, there is a significant decrease in nasal trauma [risk ratio (RR) 0.15 ; $95 \%$ confidence interval $(\mathrm{CI}) 0.01-0.60]$. HFNC is shown to have increased risk of treatment failure compared to BiPAP (RR 1.90; 95\% CI 1.24-2.81) and increased risk of treatment failure (RR 2.34 95\% CI 1.59-3.33) and need for MV (RR 1.54; 95\% CI 1.04-2.31) compared to NIPPV [5]. When used as a primary mode of respiratory support for RDS, HFNC was found to have higher failure rates compared to nCPAP (RR 1.86; 95\% CI 1.53-2.25) [6]. However, most neonates could be rescued using nCPAP and there was no increase in need for MV or surfactant administration. In postextubation settings, HFNC has similar efficacy compared to variable-flow CPAP (VF-CPAP), continuous flow CPAP, and BiPAP. When HFNC was used as a stepdown for weaning from nCPAP, a significant reduction in postmenstrual age (PMA) at weaning was noted [mean difference (MD) $-2.70 \mathrm{wk} ; 95 \%$ CI -8.37 to $-1.52 \mathrm{wk}$. However, there was a significantly longer duration of oxygen supplementation (MD $7.80 \mathrm{~d}$; 95\% CI 5.31-10.28 d) [7].

\section{Nasal Continuous Positive Airway Pressure (nCPAP)}

Nasal CPAP is a method of delivering nasopharyngeal pressure to a spontaneously breathing neonate, where pressure is maintained throughout the respiratory cycle (both inspiration and expiration). Nasal CPAP works by decreasing airway resistance, increasing functional residual capacity, stabilizing chest wall, and splinting the airway (upper and lower). The 
devices delivering nCPAP are classified into "continuousflow" and "variable-flow" devices.

\section{Continuous-Flow CPAP (CF-CPAP)}

Bubble CPAP (bCPAP) and ventilator CPAP are the two methods of delivering CF-CPAP. In bCPAP, the distal end of the expiratory limb is submerged into water to a depth equal to the CPAP provided in both phases of respiration. In ventilator CPAP, the ventilator alters the CPAP provided by altering the size of the expiratory orifice. The chest vibrations provided by bCPAP likely have a role in gas exchange [8]. Similar to HFNC, bCPAP has a flow generator, an air-oxygen blender, and a heater-humidifier (Fig. 1). In addition, the circuit has an expiratory limb in CF-CPAP devices. bCPAP is one of the commonly used, cost-effective methods of providing respiratory support to neonates. It is the respiratory support of choice for preterm neonates with respiratory distress and term neonates with moderate to severe respiratory distress.

Nasal CPAP is usually started at a pressure of $5 \mathrm{~cm} \mathrm{H}_{2} \mathrm{O}$, flow of $5 \mathrm{~L} / \mathrm{min}$ and fraction of inhaled oxygen $\left(\mathrm{FiO}_{2}\right)$ of $30 \%$. Following this, the CPAP is titrated to reduce the work of breathing, flow to obtain adequate bubbling (continuous bubbling in both phases of respiration) and $\mathrm{FiO}_{2}$ to achieve the saturation targets (90\%-95\% for preterm neonates).

In neonates with RDS, nCPAP is shown to reduce need for MV (RR 0.50; 95\% CI 0.42-0.59), surfactant administration (RR 0.54; 95\% CI 0.40-0.73) and incidence of BPD (RR 0.89; 95\% CI 0.79-0.99) [9]. Compared to BiPAP, nCPAP has higher failure rates (RR 1.44; 95\% CI 1.07-1.93), but the need for MV, air leaks, mortality, and BPD were not different. Compared to NIMV, there is a significant increase in risk of treatment failure, need for MV, air leaks, and mortality. No difference in BPD is noted [5].

CF-CPAP has similar efficacy compared to HFNC and BiPAP in preventing extubation failures. However, it is inferior to VF-CPAP (RR 1.41; 95\% CI 1.01-1.93), nonsynchronized NIPPV (RR 2.41, 95\% CI 1.50-3.75), nHFOV (RR 2.73; 95\% CI 1.23-5.49) and synchronized NIPPV (RR 5.01; 95\% CI 2.84-8.62) in preventing extubation failures [10].

Early initiation of CPAP is likely to recruit alveoli better and attain functional residual capacity faster. However, there is insufficient evidence to determine whether early initiation of CPAP is better than delayed initiation of CPAP [11]. Although the CPAP needs to be titrated based on the respiratory distress in the neonate, initiating CPAP at higher pressures ( $7 \mathrm{~cm}$ water compared to $5 \mathrm{~cm}$ water) did not result in any benefits [12]. Although excessive bubbling is not desirable, a fixed flow of $5 \mathrm{~L} / \mathrm{min}$ is shown to deliver better pressure compared to flow titrated according to visible bubbling [13]. Neonates managed on bCPAP are noted to be at decreased risk of CPAP failure [odds ratio (OR) 0.75; $95 \%$ CI 0.57-0.98]. However, they are more likely to have nasal injury, and there was no difference in clinically important outcomes of BPD or mortality [14]. When compared with hood box oxygen, nCPAP use in neonates with meconium aspiration syndrome (MAS) has shown to reduce need for $\mathrm{MV}$, surfactant therapy, and duration of oxygen therapy. No difference was noted in the incidence of PPHN and duration of hospital stay [15].

\section{Variable-Flow CPAP (VF-CPAP)}

In VF-CPAP, various mechanisms are used to generate pressure at the airway proximal to nostrils. Infant flow driver (IFD) and Benveniste gas-jet valve CPAP are the two devices used to deliver VF-CPAP. In IFD, the Bernoulli effect (gas flow is directed towards the nares) during inspiration and the Coanda effect (fluidic flip of inhaled air into the expiratory limb) during expiration maintain stable CPAP throughout the respiratory cycle. The Benveniste valve system uses the Venturi principle by utilizing two coaxial tubes connected by a ring [8]. The use of VF-CPAP has shown to decrease the work of breathing by about $13 \%$ to $29 \%$ when compared with CF-CPAP [16].

In VF-CPAP, the flow rates are titrated to attain the desired pressures, ranging from 4 to $7 \mathrm{~cm} \mathrm{H}_{2} \mathrm{O}$. The $\mathrm{FiO}_{2}$ is titrated according to the saturation measured by pulse oximetry $\left(\mathrm{SpO}_{2}\right)$ targets.

On comparison with bCPAP in preterm neonates with RDS and a gestational age less than 34 wk, VF-CPAP was noted to have similar CPAP failure rates [17]. The jet-CPAP system was noted to have lesser nasal injury and lower pain scores, although the prong displacements were more frequent [18].

\section{Nasal Bilevel Positive Airway Pressure (nBiPAP)}

In BiPAP, cycles of high and low positive airway pressures are delivered at preset rates. Compared to NIPPV, the pressures delivered are lower, high and low pressures do not differ by more than $3-4 \mathrm{~cm} \mathrm{H}_{2} \mathrm{O}$, inspiratory time (Ti) is longer $(0.5-1 \mathrm{~s})$ and rates are lower (10-30/min) [19].

It needs a stand-alone machine to deliver BiPAP, although some ventilators can deliver both NIMV and BiPAP.

In term neonates with respiratory distress, BiPAP as compared to nCPAP was shown to result in better $\mathrm{CO}_{2}$ levels and lower $\mathrm{FiO}_{2}$ requirement. However, no difference in clinically important outcomes of duration of respiratory support, need for MV and air leaks was noted [20]. 


\section{Nasal Intermittent Positive Pressure Ventilation (NIPPV)}

In NIPPV, the pressure is delivered at two levels [peak inspiratory pressure (PIP) and PEEP] using a mechanical ventilator, by modulating the gas flow and orifice of the expiratory valve. The various mechanisms by which NIPPV acts (in addition to nCPAP) include improved respiratory drive, providing higher mean airway pressure, and inducing Head's paradoxical reflex [21]. The administration of NIPPV can be synchronized with baby's respiratory effort by various methods like pneumatic capsule, pneumotachograph (flow-trigger), respiratory inductance plethysmograph, or pressure triggering.

In NIPPV, the settings mimic invasive ventilation. The Ti used are shorter compared to $\operatorname{BiPAP}(0.3-0.5 \mathrm{~s})$, inflation rates are higher (30-60/min), PEEPs are $4-7 \mathrm{~cm} \mathrm{H}_{2} \mathrm{O}$ and PIPs are 14-20 $\mathrm{cm} \mathrm{H}_{2} \mathrm{O}$. The flow rates are either in the range of 8$12 \mathrm{~L} / \mathrm{min}$ or auto-set by the ventilator.

\section{Nonsynchronized NIPPV (nsNIPPV)}

In the network meta-analysis, when used for RDS, NIPPV was found to have lesser treatment failures (RR $0.42 ; 95 \%$ CI $0.30-0.63$ ) and lesser need for MV (RR 0.65; 95\% CI 0.43-0.96) compared to HFNC. However, there was no difference in rates of air leaks, BPD, mortality, and nasal trauma. When compared to CPAP, NIPPV use results in a reduced risk of treatment failures (RR 0.56 ; 95\% CI 0.44-0.71), MV (RR 0.60 ; $95 \%$ CI $0.44-0.77$ ), air leaks (RR 0.54 ; 95\% CI 0.30 0.87 ) and mortality (RR 0.60 ; 95\% CI $0.37-0.89$ ) [5].

\section{Synchronized NIPPV (sNIPPV)}

In a randomized controlled trial (RCT) comparing SNIPPV with nCPAP in preterm neonates with RDS, neonates managed on SNIPPV had lower rates of respiratory support failure, hypercarbia, and hypoxia [22]. Also, sNIPPV was shown to decrease work of breathing compared to nCPAP [23]. A single RCT with small sample size compared SNIPPV with nsNIPPV and nCPAP in neonates with apneas. SNIPPV had a significantly lesser number of central apneas, median event rates of desaturations, and bradycardia [24]. In the network meta-analysis comparing different modes of respiratory support post-extubation in neonates, SNIPPV is shown to be more effective than HFNC, CPAP, BiPAP, and nsNIPPV [10]. The current evidence does not suggest its superiority over nHFOV.

\section{Nasal High-Frequency Oscillatory Ventilation (nHFOV)}

nHFOV combines the benefits of high-frequency ventilation and nasal ventilation. Similar to invasive HFOV, the delivery of small tidal volumes at supraphysiological rates results in better $\mathrm{CO}_{2}$ elimination.
For nHFOV, most studies have used frequencies ranging from 5 to $12 \mathrm{~Hz}$, flow rates of 8-12 L/min, inspiratory:expiratory times of 1:1, mean airway pressure (MAP) based on the clinical status of the neonate, and amplitude of 2-3 times that of MAP. The amplitude is further titrated to attain visible chest oscillations [25].

A meta-analysis of 8 RCTs including 463 preterm neonates showed that nHFOV results in a lesser likelihood of MV $(\mathrm{RR}=0.50 ; 95 \% \mathrm{CI} 0.36$ to 0.70$)$ and better $\mathrm{CO}_{2}$ removal [mean difference (MD) $-4.6 \mathrm{mmHg}$; $95 \% \mathrm{CI}-7.9$ to -1.3 ] when compared with nCPAP or nBiPAP [25].

\section{Nasal Neurally Adjusted Ventilatory Assist (nNAVA)}

In nNAVA, the ventilator is cycled by the electrical activity of the diaphragm (EADi). The signal is sensed by electrodes embedded in the nasogastric feeding tube and positioned at the level of crura of diaphragm. The above mechanism places nNAVA at an inherent disadvantage when being administered to babies with frequent central apneas and other causes of central hypo/hyperventilation (intraventricular hemorrhage, sedation, phrenic nerve injury, etc).

For nNAVA, the settings of PEEP and $\mathrm{FiO}_{2}$ are similar to NIPPV. The EADi trigger, the diaphragmatic activity at which the ventilator starts delivering a breath, is usually set at $0.5 \mu \mathrm{V}$. The cycling of the respiratory cycle, by default, is set at $30 \%$ of peak EADi. The assist or NAVA level, which determines the proportionality between EADi and the ventilator pressure, is set at $2 \mathrm{~cm} \mathrm{H}_{2} \mathrm{O} / \mu \mathrm{V}$, and titrated by $0.5 \mathrm{~cm}$ $\mathrm{H}_{2} \mathrm{O} / \mu \mathrm{V}$ till the neonate is comfortable and peak EADi is $<15 \mu \mathrm{V}[26]$.

\section{Nasal Interfaces to Deliver NIV (Fig. 2)}

The interfaces used may be device specific or may be compatible with multiple devices. When providing respiratory support with HFNC, the interface should be nonocclusive allowing entrainment of air around the cannula. When providing the other modes of noninvasive support, a tight seal is needed to deliver the set pressures. Interfaces like Hudson prongs and nasal mask can be used for delivering nCPAP, NIPPV, BiPAP, and nHFOV. Ram cannula is suitable, and Food and Drug Administration (FDA) approved for providing HFNC. But it is frequently used off-label, with some modifications to achieve near complete nasal seal, for administration of nCPAP and NIPPV.

Optiflow, as an interface is used exclusively for proving HFNC. It is available in two different color codes-red color for preterm and yellow color for term neonates. It has an anatomically contoured, breathable, kink-proof, and crushresistant tubing, with an easy click connector, which rotates with the movement of the neonate. It also has self-adhesive 
Fig. 2 Nasal interfaces used for noninvasive respiratory support for neonates (close up at the inserts). a Ram cannula, a modified version of short binasal prongs $\left(\right.$ Neotech $\left.^{\mathrm{TM}}\right)$, b Fisher and Paykel ${ }^{\mathrm{TM}}$ short binasal prongs,

c Dräger ${ }^{\mathrm{TM}}$ nasal mask, d Optiflow ${ }^{\mathrm{TM}}$ nasal cannula used as high-flow nasal cannula
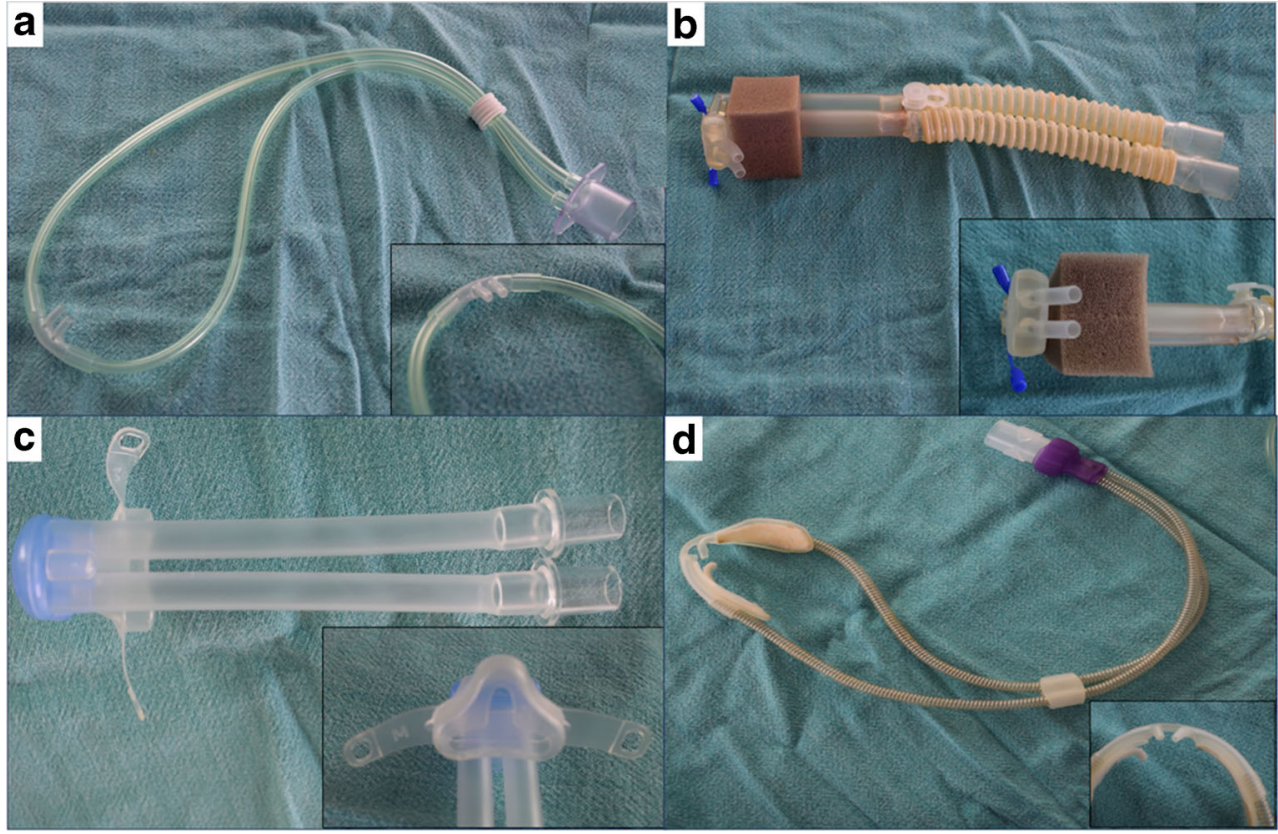

wiggle pads which maintain stability of the interface. It provides better access to the neonate; eases nursing care and improves parental involvement in baby care. Nasal mask is one of the most effective ways to deliver noninvasive respiratory support. When used as an interface for nCPAP, nasal mask has decreased rates of CPAP failure (RR 0.72; 95\% CI $0.53-0.97$ ) and nasal injury (RR $0.71 ; 95 \%$ CI 0.59-0.85). However, it is cumbersome and difficult to maintain with frequent displacements. Thus, it needs good and intensive nursing care and monitoring. Hudson prongs, the most commonly used short binasal prongs, are anatomically curved prongs available in six different sizes. This allows for better choice for appropriate sizing of the prongs for each infant. They are effective and safe for use in neonates. Ram cannula is originally approved for delivering gases at low or high flows. However, because of the ease of use and lower nasal trauma, it is often used off-label for delivering nCPAP, NIPPV, and nHFOV. Ram cannula looks similar to a traditional nasal cannula, but its stiffer design and higher diameter allows for delivery of higher flow and pressure. However, the pressures delivered by Ram cannula were found to be less than the Hudson prong and nasal masks [27]. There is no data to support use of Ram cannula in smallest of the babies and it has to be used with caution in extremely low-birth-weight (ELBW) neonates. Other interfaces like nasopharyngeal prongs and single nasal prongs are not recommended for use.

\section{Optimizing the Use of NIV (Figs. 3 and 4)}

Early initiation of respiratory support helps in maintaining the functional residual capacity and preventing alveolar
Fig. 3 Algorithm for managing preterm neonates with respiratory distress using noninvasive respiratory support.

$C P A P$ Continuous positive airway pressure; $D R$ Delivery room; $\mathrm{FiO}_{2}$ Fraction of inhaled oxygen; HFNC High-flow nasal cannula; NICU Neonatal intensive care unit; $P P V$ Positive pressure ventilation; $R D S$ Respiratory distress syndrome

\begin{tabular}{|c|c|c|}
\hline $\begin{array}{l}\text { Low-risk neonates } \\
\text { - }>1.5 \mathrm{~kg} \\
\text { - }>32 \mathrm{wk} \\
\text { - Antenatal steroid } \\
\text { cover } \\
\text { - No chorioamnionitis }\end{array}$ & $\begin{array}{ll} & \begin{array}{c}\text { Moderate-risk } \\
\text { neonates }\end{array} \\
\cdot & 1.0-1.5 \mathrm{~kg} \\
\cdot & 28-32 \mathrm{wk} \\
\cdot & \text { Steroid cover + } \\
\cdot & >32 \mathrm{wk} / 1.5 \mathrm{~kg} \text { with } \\
& \text { severe distress }\end{array}$ & $\begin{array}{l}\text { High-risk neonates } \\
\cdot \quad<1 \mathrm{~kg} \\
\cdot \quad<28 \mathrm{wk} \\
\cdot \text { Need for PPV in DR } \\
\cdot \text { Severe RDS } \\
\text { - } \quad \text { No steroid cover } \\
\text { - } \quad \text { Chorioamnionitis + }\end{array}$ \\
\hline \multirow{4}{*}{ Initiate on HFNC/CPAP } & \multirow{3}{*}{$\begin{array}{l}\text { Initiate on DR-CPAP } \\
\text { Continue CPAP in NICU } \\
\text { Caffeine } \\
\text { Early rescue surfactant }\end{array}$} & \multirow{4}{*}{$\begin{array}{l}\text { Initiate on DR-CPAP } \\
\text { Initiateon CPAP/NIPPV } \\
\text { Caffeine } \\
\text { Antibiotics (as indicated) } \\
\text { Early rescue surfactant }\end{array}$} \\
\hline & & \\
\hline & & \\
\hline & & \\
\hline \\
\hline \multicolumn{3}{|c|}{$\begin{array}{c}\text { Meticulous monitoring using objective scores } \\
\text { Titration of pressure, } \mathrm{FiO}_{2} \text { and flow as appropriate } \\
\text { Supportive care (developmentally supportive, nasal trauma prevention, nutrition) }\end{array}$} \\
\hline
\end{tabular}


collapse at the end of expiration. Early nCPAP (initiated at 5 min after birth) reduced need for MV and surfactant therapy when compared with late nCPAP initiation (initiated after $30 \mathrm{~min}$ of birth) [28]. For preterm neonates with RDS, nCPAP may be better than HFNC because of lesser failure rates. In ELBW neonates, with inadequate antenatal steroid cover and more severe distress, NIPPV may be a better NIV choice. For delivering HFNC, binasal prongs with a nasal seal of about $50 \%$ are recommended (Optiflow, Ram cannula). For other modes of noninvasive respiratory support, snugly fitting prongs are recommended. For ELBW neonates, use of nasal mask may be preferred because of better pressure delivery [27], lower failure rates, and lesser nasal trauma [29]. Humidification and

\section{ApPlicATION Of BUBble CPAP FOR NEWBORN}

INDICATIONS :

Respiratory Distress :

- Preterm Infants

(Gestation $<35$ weeks) : SAS Score $>3$

- Term Infants

(Gestation $>=35$ weeks) : SAS Score $>5$

- Recurrent Apneas in a preterm infant

- Post extubation in VLBW infant

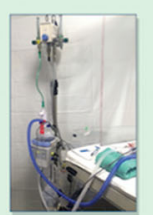

CONTRAINDICATIONS :

- Poor Respiratory efforts

- Nasal seal poor (Cleft Palate)

- Tracheo-esophageal fistula and

Congenital diaphragmatic hernia

- Pnuemothorax and other air leaks
PREPARATION OF MACHINE AND INTERFACE :

- Assemble the sterile circuit

- Fill distilled water in humidifier and clean water in bubble chamber

- Connect air and oxygen to blender, switch on the humidifier

- Fix the cap to the baby and appropriated size prongs to the cap

- Connect interface to the sterile circuit

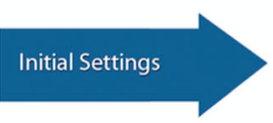

Adjustment of $\mathrm{FiO}_{2}$ and CPAP pressure

Weaning of CPAP

Failure of CPAP or Need for MV

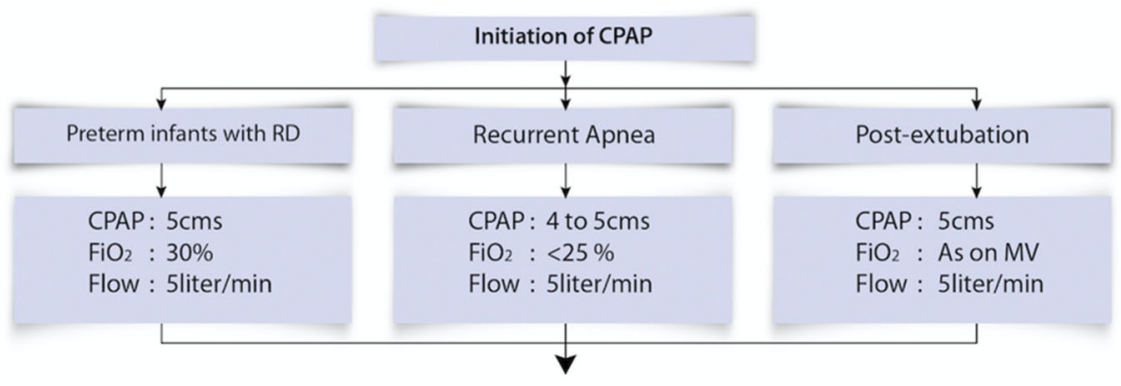

Increase CPAP in steps of $1 \mathrm{~cm}$ :

- If retractions $++\& \mathrm{SpO}_{2}<90 \%$ and Chest $x$ ray $(1 / 2$ hour after starting $)<6$ spaces Increase $\mathrm{FiO}_{2}$ in steps of $5 \%$

- If mild or no retractions and $\mathrm{SpO}_{2}<90 \%$

- For every $10 \%$ increase in $\mathrm{FiO}_{2}$ assess the need for increase in CPAP pressure by $1 \mathrm{~cm}$

No change in CPAP or $\mathrm{FiO}_{2}$ is required if baby is comfortable, minimal or no retractions, CFT and $\mathrm{BP}$ are normal, $\mathrm{SpO}_{2}$ between 90 to $95 \%$, bubbling is good and breath sounds are heard

- Ensure correct size and fixation of nasal prongs

- Ensure gap between columella and nasal prongs

- Fix the prongs to cap and cover ears with cap

- Remove prongs, inspect nostrils, use saline drops if needed and do gentle massage in each shift

- Ensure water level in bubble chamber and Humidifier

- Record depth of immersion of expiratory limb

- Maintain monitoring sheet

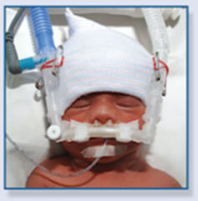

$\mathrm{CPAP}$ and $\mathrm{FiO}_{2}$ :

- Reduce $\mathrm{FiO}_{2}$ if $\mathrm{SpO}_{2}>95 \%$ in steps of $5 \%$

- If $\mathrm{FiO}_{2}$ reduced by $10 \%$ and retractions are mild or absent, reduce CPAP pressure by $1 \mathrm{~cm}$ till CPAP is $5 \mathrm{~cm}$ and $\mathrm{FiO}_{2}$ is $50 \%$

- Subsequently reduce $\mathrm{FiO}_{2}$ in steps of $5 \%$ till $\mathrm{FiO}_{2}<30 \%$ before reducing CPAP pressure from $5 \mathrm{~cm}$ to $4 \mathrm{~cm}$ of water

- Remove CPAP if $\mathrm{FiO}_{2}$ is $<25 \%$ and CPAP is $4 \mathrm{~cm}$

- $\mathrm{SpO}_{2}<90 \%$ on $\mathrm{FiO}_{2}>70 \%$ and $\mathrm{CPAP}>7 \mathrm{~cm}$

- Moderate to severe retractions on $C P A P>7 \mathrm{~cm}$

- Recurrent Apneas

- Shock or multiorgan dysfunction

- Poor respiratory efforts or $\mathrm{PaCO}_{2}>60 \mathrm{~mm}$ of $\mathrm{Hg}$

Fig. 4 A guide for initiation and titration of nasal continuous positive airway pressure. $B P$ Blood pressure; $C F T$ Capillary filling time; $C P A P$ Continuous positive airway pressure; $\mathrm{FiO}_{2}$ Fraction of inhaled oxygen;
$M V$ Mechanical ventilation; $\mathrm{PaCO}_{2}$ Partial pressure of arterial carbon dioxide; $R D$ Respiratory distress; $\mathrm{SAS}$ Silverman-Anderson score; $\mathrm{SpO}_{2}$ Saturation measured by pulse oximetry; $V L B W$ Very low birth weight 
warming of the inhaled gases protects the mucociliary system of the nasal mucosa [30], decreases incidence of hypothermia related to inhalation of cold gases [31], and improves the neonatal outcomes. A relative humidity of $100 \%$ should be delivered at a temperature of $37^{\circ} \mathrm{C}$ for all neonates on noninvasive respiratory support (similar to invasive mode of ventilation). Meticulous monitoring is needed for neonates on noninvasive respiratory support (Fig. 3). One of the main problems with nCPAP is the failure rates and need for invasive ventilation. The failure rates with nCPAP are reported to be around 31\%-83\% [32]. The risk factors for nCPAP failure include a weight below $750 \mathrm{~g}$, need for positive pressure ventilation during resuscitation, severe RDS on radiography [33], need for $\mathrm{FiO}_{2}>30 \%$ [34], and recurrent apnea. Such neonates should be escalated to NIPPV as appropriate. Early rescue surfactant, administered with in $2 \mathrm{~h}$ of onset of respiratory distress, reduces risk of mortality, air leaks, and BPD [35]. Early caffeine also reduces BPD, patent ductus arteriosus, postnatal steroid use, retinopathy of prematurity, and brain injury [36].

\section{Supportive Care}

The maintenance of noninvasive respiratory support equipment and appropriate cleaning has to be done on a regular basis. The training of nurses for managing neonates on noninvasive support decreases the incidence of nasal trauma [37]. Quality improvement measures like using a nCPAP cart, prepacked fixation kits, a written nursing protocol, ensuring adherence to manufacturers recommendations and evidence-based checklists are effective measures to expedite nCPAP initiation and decrease nasal trauma $[38,39]$. Monitoring of neonate on NIV includes observation of adequacy of respiratory settings, nasal interface for nasal injury, and comfort of the neonate. A structured and objective monitoring of these parameters using monitoring charts is very essential (Nasal Injury Assessment score in Table 1). Similarly, the circuit has to be looked at for adequacy of heating and humidification, presence of any leaks in the circuit, and presence of condensation/misting in the inspiratory or expiratory limbs. The neonate can be uncomfortable because of various reasons including inadequate heating or humidification, nasal injury, hunger, improper positioning, separation from mother, and environmental factors like excess sound and/or light. Various developmentally supportive care practices like mimicking the in-utero posture (nesting and swaddling), decreasing ambient lighting and noise levels, preventing and managing neonatal pain, and improving mother-baby interaction (kangaroo mother care, skin-to-skin contact) need to be incorporated into care of neonates on respiratory support.
Table 1 Nasal Injury Assessment score chart

\begin{tabular}{ll}
\hline Tip of nose & $=$ Normal \\
1 & $=$ Red \\
2 & $=$ Red + indent \\
3 & $=$ Red/indent/skin breakdown \\
4 & $=$ As above + tissue loss \\
0 & $=$ Normal \\
1 & $=$ Red \\
2 & $=$ Red + indent \\
3 & $=$ Red/indent/skin breakdown \\
4 & $=$ As above + tissue loss \\
& $0=$ Normal \\
1 & $=$ Enlarged \\
2 & $=$ Enlarged and prong shape \\
3 & $=$ Red, bleeding \\
4 & $=$ As above + skin breakdown \\
0 & $=$ Normal \\
1 & $=$ Pushed up/back but normal \\
2 & $=$ Pushed up and shortened. No normal \\
& orientation when prongs removed. \\
0 & $=$ Normal \\
1 & $=$ Red \\
2 & $=$ Red + indent \\
3 & $=$ Red/indent/skin breakdown \\
4 & $=$ As above + tissue loss \\
0 & $=$ Normal \\
1 & $=$ Red \\
2 & $=$ Red + indent \\
3 & $=$ Red/indent/skin breakdown \\
4 & $=$ As above + tissue loss \\
Nose shape & Bridge of the nose
\end{tabular}

Scoring: $0=$ no injury, $1-4=$ mild injury, $5-6=$ moderate injury, $>7=$ severe injury

\section{Conclusions}

Noninvasive respiratory is the standard respiratory support for preterm and term infants. Type of NIV used is based on the severity of respiratory distress, risk of treatment failure, gestational age, and timing of application. HFNC, CPAP, NIPPV (synchronized or nonsynchronized) are the most commonly used NIV in the newborn. BiPAP, Nasal HFOV and NAVA are infrequently used and need further evaluation before routine application. Early initiation, adequate and aggressive use of surfactant/caffeine, optimum warmidification, appropriate nasal interface, and nursing care are crucial in the success of NIV.

Authors' Contribution RPA conceptualized the study, collected the data, prepared the figures and wrote the manuscript; SM conceptualized the study, gave inputs to manuscript, and approved the final version of the manuscript. SM will act as the guarantor for this paper. 


\section{Declarations}

Conflict of Interest None.

\section{References}

1. Gregory GA, Kitterman JA, Phibbs RH, Tooley WH, Hamilton WK. Treatment of the idiopathic respiratory-distress syndrome with continuous positive airway pressure. N Engl J Med. 1971;284: 1333-40.

2. Rhodes PG, Hall RT. Continuous positive airway pressure delivered by face mask in infants with the idiopathic respiratory distress syndrome: a controlled study. Pediatrics. 1973;52:1-5.

3. Dunn PM. Respiratory distress syndrome. Continuous positive airway pressure (CPAP) using the Gregory box. Proc R Soc Med. 1974;67:245-7.

4. Avery ME, Tooley WH, Keller JB, et al. Is chronic lung disease in low birth weight infants preventable? A survey of eight centers. Pediatrics. 1987;79:26-30.

5. Ramaswamy VV, More K, Roehr CC, Bandiya P, Nangia S. Efficacy of noninvasive respiratory support modes for primary respiratory support in preterm neonates with respiratory distress syndrome: systematic review and network meta-analysis. Pediatr Pulmonol. 2020;55:2940-63.

6. Lin X, Jia P, Li X-Q, Liu Q. Efficacy of high-flow nasal cannula versus nasal continuous positive airway pressure in the treatment of respiratory distress syndrome in neonates: a meta analysis. Zhongguo Dang Dai Er Ke Za Zhi. 2020;22:1164-71.

7. van Delft B, Ginderdeuren FV, Lefevere J, van Delft C, Cools F. Weaning strategies for the withdrawal of non-invasive respiratory support applying continuous positive airway pressure in preterm infants: a systematic review and meta-analysis. BMJ Paediatr Open. 2020;4:e000858.

8. Gupta S, Donn SM. Continuous positive airway pressure: physiology and comparison of devices. Semin Fetal Neonatal Med. 2016;21:204-11.

9. Subramaniam P, Ho JJ, Davis PG. Prophylactic nasal continuous positive airway pressure for preventing morbidity and mortality in very preterm infants. Cochrane Database Syst Rev. 2016;6: CD001243.

10. Ramaswamy VV, Bandyopadhyay T, Nanda D, et al. Efficacy of noninvasive respiratory support modes as postextubation respiratory support in preterm neonates: a systematic review and network meta-analysis. Pediatr Pulmonol. 2020;55:2924-39.

11. Ho JJ, Subramaniam P, Sivakaanthan A, Davis PG. Early versus delayed continuous positive airway pressure (CPAP) for respiratory distress in preterm infants. Cochrane Database Syst Rev. 2020;10: CD002975.

12. Murki S, Nathani PP, Sharma D, Subramaniam S, Oleti TP, Chawla D. Initiating nasal continuous positive airway pressure in preterm neonates at $5 \mathrm{~cm}$ as against $7 \mathrm{~cm}$ did not decrease the need for mechanical ventilation. Acta Paediatr. 2016;105:e345-51.

13. Murki S, Das RK, Sharma D, Kumar P. A fixed flow is more effective than titrated flow during bubble nasal CPAP for respiratory distress in preterm neonates. Front Pediatr. 2015;3:81.

14. Bharadwaj SK, Alonazi A, Banfield L, Dutta S, Mukherji A. Bubble versus other continuous positive airway pressure forms: a systematic review and meta-analysis. Arch Dis Child Fetal Neonatal Ed. 2020;105:526-31.

15. Pandita A, Murki S, Oleti TP, et al. Effect of nasal continuous positive airway pressure on infants with meconium aspiration syndrome: a randomized clinical trial. JAMA Pediatr. 2018;172:161-5.
16. Pandit PB, Courtney SE, Pyon KH, Saslow JG, Habib RH. Work of breathing during constant- and variable-flow nasal continuous positive airway pressure in preterm neonates. Pediatrics. 2001;108: $682-5$.

17. Bhatti A, Khan J, Murki S, Sundaram V, Saini SS, Kumar P. Nasal jet-CPAP (variable flow) versus bubble-CPAP in preterm infants with respiratory distress: an open label, randomized controlled trial. J Perinatol. 2015;35:935-40.

18. Khan J, Sundaram V, Murki S, Bhatti A, Saini SS, Kumar P. Nasal injury and comfort with jet versus bubble continuous positive airway pressure delivery systems in preterm infants with respiratory distress. Eur J Pediatr. 2017;176:1629-35.

19. Permall DL, Pasha AB, Chen X. Current insights in non-invasive ventilation for the treatment of neonatal respiratory disease. Ital $\mathrm{J}$ Pediatr. 2019;45:105.

20. Cimino C, Saporito MAN, Vitaliti G, et al. N-BiPAP vs n-CPAP in term neonate with respiratory distress syndrome. Early Hum Dev. 2020;142:104965.

21. Owen LS, Morley CJ, Davis PG. Neonatal nasal intermittent positive pressure ventilation: what do we know in 2007? Arch Dis Child Fetal Neonatal Ed. 2007;92:F414-8.

22. Gao WW, Tan SZ, Chen YB, Zhang Y, Wang Y. Randomized trail of nasal synchronized intermittent mandatory ventilation compared with nasal continuous positive airway pressure in preterm infants with respiratory distress syndrome. Zhongguo Dang Dai Er Ke Za Zhi. 2010;12:524-6.

23. Aghai ZH, Saslow JG, Nakhla T, et al. Synchronized nasal intermittent positive pressure ventilation (SNIPPV) decreases work of breathing (WOB) in premature infants with respiratory distress syndrome (RDS) compared to nasal continuous positive airway pressure (NCPAP). Pediatr Pulmonol. 2006;41:875-81.

24. Gizzi C, Montecchia F, Panetta V, et al. Is synchronised NIPPV more effective than NIPPV and NCPAP in treating apnoea of prematurity (AOP)? A randomised cross-over trial. Arch Dis Child Fetal Neonatal Ed. 2015;100:F17-23.

25. Li J, Li X, Huang X, Zhang Z. Noninvasive high-frequency oscillatory ventilation as respiratory support in preterm infants: a metaanalysis of randomized controlled trials. Respir Res. 2019;20:58.

26. Firestone KS, Beck J, Stein H. Neurally adjusted ventilatory assist for noninvasive support in neonates. Clin Perinatol. 2016;43:707-24.

27. Sharma D, Murki S, Maram S, et al. Comparison of delivered distending pressures in the oropharynx in preterm infant on bubble CPAP and on three different nasal interfaces. Pediatr Pulmonol. 2020;55:1631-9.

28. Badiee Z, Naseri F, Sadeghnia A. Early versus delayed initiation of nasal continuous positive airway pressure for treatment of respiratory distress syndrome in premature newborns: a randomized clinical trial. Adv Biomed Res. 2013;2:4.

29. King BC, Gandhi BB, Jackson A, Katakam L, Pammi M, Suresh G. Mask versus prongs for nasal continuous positive airway pressure in preterm infants: a systematic review and meta-analysis. Neonatology. 2019;116:100-14.

30. Schiffmann H. Humidification of respired gases in neonates and infants. Respir Care Clin N Am. 2006;12:321-36.

31. Meyer MP, Hou D, Ishrar NN, Dito I, te Pas AB. Initial respiratory support with cold, dry gas versus heated humidified gas and admission temperature of preterm infants. J Pediatr. 2015;166:245250.e1.

32. Shi Y, Muniraman H, Biniwale M, Ramanathan R. A review on non-invasive respiratory support for management of respiratory distress in extremely preterm infants. Front Pediatr. 2020;8:270.

33. Ammari A, Suri M, Milisavljevic V, et al. Variables associated with the early failure of nasal CPAP in very low birth weight infants. J Pediatr. 2005;147:341-7.

34. Gulczyńska E, Szczapa T, Hożejowski R, BorszewskaKornacka MK, Rutkowska M. Fraction of inspired oxygen 
as a predictor of CPAP failure in preterm infants with respiratory distress syndrome: a prospective multicenter study. Neonatology. 2019;116:171-8.

35. Bahadue FL, Soll R. Early versus delayed selective surfactant treatment for neonatal respiratory distress syndrome. Cochrane Database Syst Rev. 2012;11:CD001456.

36. Kua KP, Lee SWH. Systematic review and meta-analysis of clinical outcomes of early caffeine therapy in preterm neonates. Br J Clin Pharmacol. 2017;83:180-91.

37. Naha N, Pournami F, Prabhakar J, Jain N. Nasal injury with continuous positive airway pressure: need for "privileging" nursing staff. Indian J Pediatr. 2019;86:595-8.
38. Chen C-Y, Chou A-K, Chen Y-L, Chou H-C, Tsao P-N, Hsieh W$\mathrm{S}$. Quality improvement of nasal continuous positive airway pressure therapy in neonatal intensive care unit. Pediatr Neonatol. 2017;58:229-35.

39. Mariam S, Buddhavarapu S. Impact of systematic training and CPAP checklist in the prevention of NCPAP related nasal injuries in neonates- a quality improvement study. Indian J Pediatr. 2020;87:256-61.

Publisher's Note Springer Nature remains neutral with regard to jurisdictional claims in published maps and institutional affiliations. 